\title{
CHADS2-VASC Score as a Predictor for Contrast Induced Nephropathy in Patient with Acute Myocardial Infarction Treated with Primary Percutaneous Coronary Intervention
}

\author{
AHMED F. ABO EGELA, M.Sc.; MAI M. SALAMA, M.D.; SUZAN B. EL HEFNAWY, M.D. and \\ MOHAMED N. HUSSIEN, M.D. \\ The Department of Cardiology, Faculty of Medicine, Tanta University
}

\begin{abstract}
Background: Ischaemic heart disease is the single most common cause of death and its frequency is increasing. Acute ST-Elevation Myocardial Infarction (STEMI) results from the sudden obstruction of a coronary artry. Acute kidney injury is a frequent complication among patients who undergo Primary Percutaneous Intervention (PCI) shown to be associated with adverse outcomes. CHADS2 and the more recent CHA2DS2-VASc are two validated scores for predicting embolic/stroke risk in patients with non-valvular Atrial Fibrillation (AF). The CHADS2-VASC score has been reported as risk factors for CIN and adverse cardiac events.

Aim of the Study: The aim of this work is to evaluate CHA2DS2-VASC score as a predictor for Contrast-Induced Nephropathy (CIN) in patient with acute myocardial infarction treated with primary Percutaneous Coronary Intervention (PCI).

Patient and Methods: The study included 100 patients presenting to Cardiology Department, Tanta University Hospital, diagnosed with as first time STEMI and underwent primary PCI. CHADS2-VASC score (age, sex, diabetes, hypertension, heart failure on admission, previous ischemic event, vascular event) was calculated for all patients. Serum creatinin level and effective Glomerular Filtration Rate (eGFR) were estimated for all patient before and $48 \mathrm{~h}$ after PPCI.
\end{abstract}

They were divided into into two groups: Group I: Those who developed CIN $48 \mathrm{~h}$ after primary PCI $(36 \%)$ and Group II: Those who did not (64\%).

Results: Patient who developed CIN had higher CHADS2VASC score than who did not, mean \pm SD value was $3.53 \pm 1.11$ vs. $0.72 \pm 0.83, p$-value $<0.001$.

Conclusion: CHA2DS2-VASC score $>3$ was independently associated with CIN development in patients with acute STEMI who were treated by PPCI. The more CHADS2-VASC score, the more risk for developing CIN after PPCI.

Key Words: STEMI - CIN-CHADS2VASC score - PPCI.

Correspondence to: Dr. Ahmed F. Abo Egela, The Department of Cardiology, Tanta University Hospital

\section{Introduction}

ACUTE ST-Segment Myocardial Infarction (STE$\mathrm{MI}$ ) is one of the most important cardiovascular diseases that increase risk of morbidity and mortality [1]. The primary goal in management of acute STEMI is reperfusion therapy with intravenous fibrinolysis or Primary Percutaneous Intervention (PCI) [2]

Acute kidney injury is a frequent complication among patients who undergo primary PCI shown to be associated with adverse outcomes $[3,4]$.

The reported incidence of Contrast Induced Nephropathy (CIN) varies widely in different populations, ranging from $7 \%$ to $25 \%$, depending on the presence of risk factors. Hence, risk stratification is important, in order to apply the appropriate extent of prophylactic strategy in high-risk populations $[\mathbf{5 , 6 ]}$.

Studies have revealed many predictors for CIN after primary PCI such as red cell distribution width platelet to lymphocyte ratio, AGEF score (age, glomerular fraction, ejection fraction), one of these predictors is the CHADS VASC score [79]. The CHADS2-VASC score has been reported as risk factors for CIN and adverse cardiac events [9].

\section{Patients and Methods}

This study was conducted in the Department of Cardiovascular Medicine, Tanta University Hospital at the period between June 2017 to December 2017, it was carried out on 100 patients 
diagnosed definitively with (STEMI) and treated with primary PCI.

All patients were subjected to detailed history taking, full clinical examination, 12 lead electrocardiogram, echocardiography and primary PCI strategy. In all patients recruited in this study, CHADS2-VASC score (age, sex, DM, HTN, HF on admission, previous ischaemic event, vascular event) was calculated. Blood samples were collected on admission before PCI from the ante-cubital vein by an a traumatic puncture and were sent to the laboratory for analysis of: Serum cardiac biomarkers, renal functions (creatinin and urea levels), Glomerular Filtration Rate (GFR) is estimated for all patients before primary PCI.

All patient received $300 \mathrm{mg}$ acetyl salicylic acid, $600 \mathrm{mg}$ clopidogrel, $80 \mathrm{mg}$ of atorvastatin and unfractionated heparin as a loading dose according to the body weight. All patient underwent primary PCI and renal functions and GFR estimation before and $48 \mathrm{~h}$ post primary PCI.

The patient were divided into into two groups: Group I those who developed CIN $48 \mathrm{~h}$ after primary PCI (36\%), and Group II those who didnot (64\%).

\section{Exclusion criteria:}

Patients presented with previous STEMI, patients with chronic kidney disease (creatinine clearance $<15 \mathrm{~mL} / \mathrm{min}$ ), patients who previously underwent Coronary Artery Bypass Graft (CABG), with hematological disorders, with active hepato-biliary disease, with active infections, with neoplastic diseases and with recent major surgical procedure or trauma.

\section{Duration of the study:}

This study was done in a period of six months from June 2017 to December 2017.

\section{Statistical analysis:}

Data were fed to the computer and analyzed using IBM SPSS software package Version 20.0. Statistical presentation and analysis of the present study was conducted, using the mean, standard deviation and Chi-square test, Pearson Chi-square and likely hood-ratio chi-square, Fisher's exact test and Yates' corrected chi-square are computed for 2 X 2 tables and Standard student " $t$ test", test of significance of the difference between two means.

\section{Results}

Table (1) shows the demographic data of the studied population. Patients who developed CIN were older $65.67 \pm 9.48$ vs. $51.66 \pm 10.66, p$-value $<0.001)$, and with a more female refrence (55.6 vs. 44.4, $p$ 0.0006). Diabetes Mellitus and Hypertension were more relevant in Group I than II (72.2 vs. $25 \%$, and 80.6 vs. $14.1 \%, p<0.001$ respectively). Group I were more in class III killip classification (52.8\%-p-value $<0.001)$. They did nor show statically significant difference regarding BP, GFR before PCI, ischemic stroke and vascular event. CHAADS2-VASC score was higher in Group I patients $(3.53 \pm 1.11$ vs. $0.72 \pm 0.83, p<0.001)$.

Table (2) shows the angiographic results of the studied population. There was no statically significant difference regarding angiographic data except for total ischaemic time (3.0 $\pm 2.03 \mathrm{Vs} .2 .40 \pm 2.19$, $p<0.004$ ), TIMI flow after primary PCI (Group I had TIMI II more than Group II (33.3 vs. 15.6) while Group II had TIMI III more than Group I (84.4 vs. 66.7).

Lastly, Group I had longer inhospital stay (6.61 \pm 0.84 vs. $2.86 \pm 0.35, p<0.001)$.

Univariate and multivariate analysis for indicators of CIN:

Univariate and multivariate regression analyses were performed to investigate the possible predictors of CIN in the study population.

In univariate regression analysis, sex, age, DM, HTN, KILLIP > 2, CHADS2-VASC score, total ischemic time, TIMI flow III after PPCI corellated significantly with CIN, as shown in (Table 3 ).

In multivariate regression analysis, sex, age, DM, HTN, Killip Class >2, CHADS2-VASC score, total ischemic time, TIMI flow after primary PCI correlated significantly with occurrence of CIN.

\section{ROC curve for CHADSVASC score to predict CIN cases:}

The Receiver Operating Characteristic (ROC) analysis showing the performance and predictive accuracy of CHADSVASC in predicting CIN, the Area Under the Curve (AUC) was 0.956, 95\% Confidence Interval (CI) 0.907-1.006 ( $p<0.001)$, with cutoff value CHADSVASC more than $>3$, with $55.56 \%$ sensitivity and $98.44 \%$ specificity Fig. (1), (Table 4). 
Table (1): Compassion according to demographic data between the two studied groups.

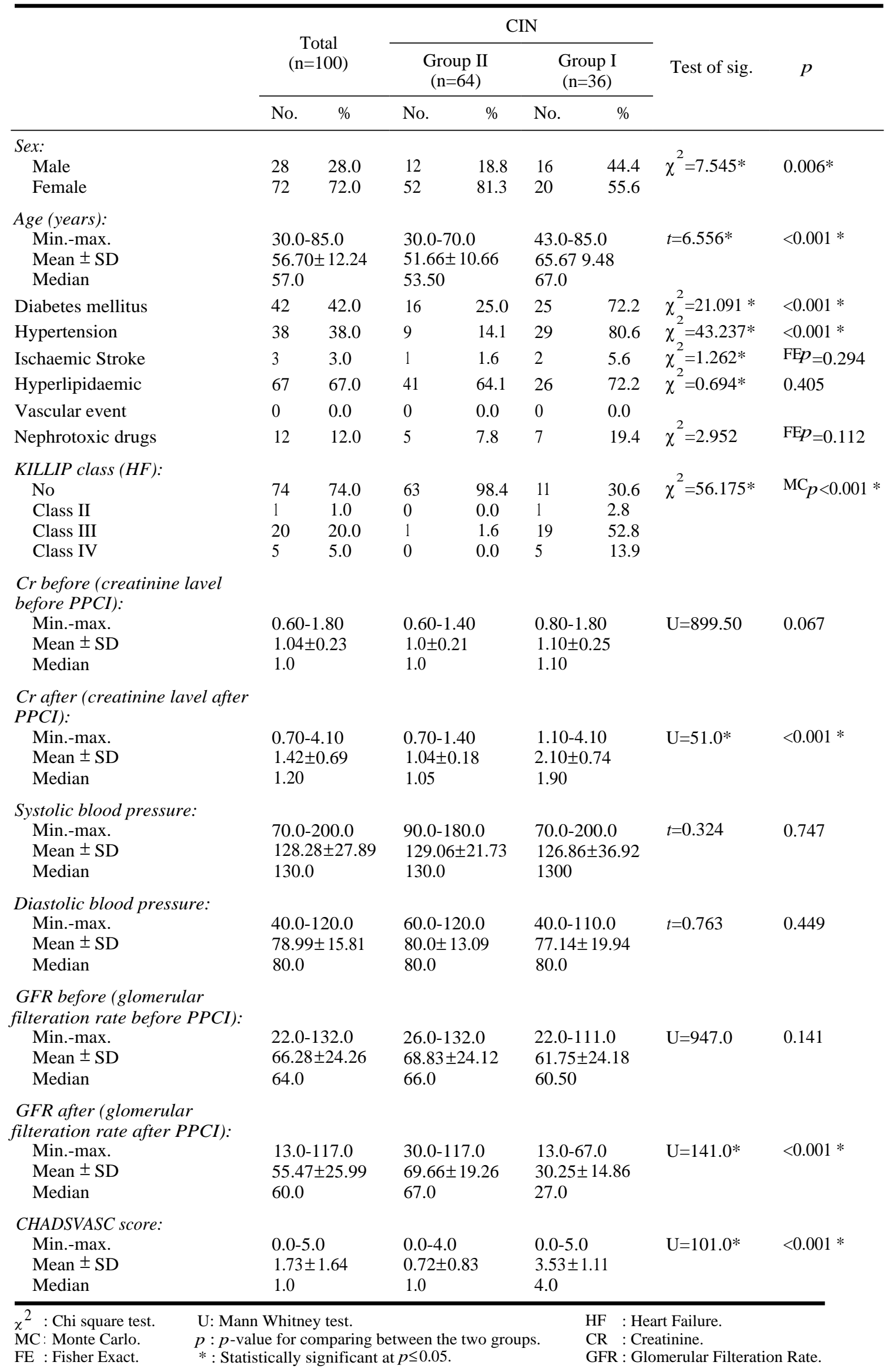


Table (2): Compassion between the two studied groups according to angiographic results.

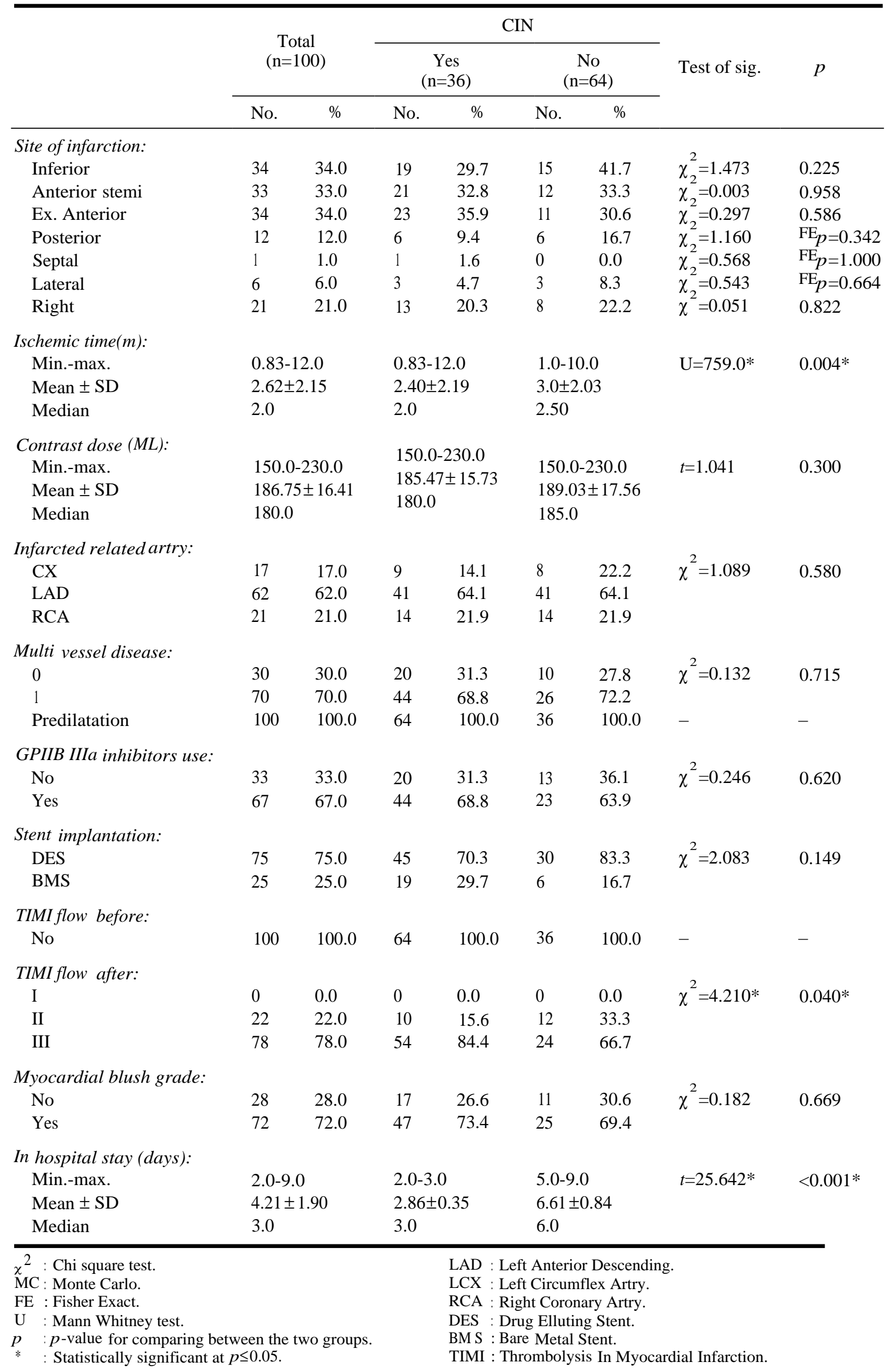


Table (3): Univariate and multivariate analysis for the parameters affecting CIN cases.

\begin{tabular}{|c|c|c|c|c|}
\hline & \multicolumn{2}{|r|}{ Univariate } & \multicolumn{2}{|r|}{ \#Multivariate } \\
\hline & $p$ & OR $(95 \%$ C.I $)$ & $p$ & OR (95\%C.I) \\
\hline Sex & $0.007 *$ & $0.288(0.116-0.716)$ & 0.852 & $1.015(0.867-1.188)$ \\
\hline Age (years) & $<0.001 *$ & $1.148(1.083-1.216)$ & 0.924 & $0.686(0.047-16.146)$ \\
\hline $\mathrm{DM}$ & $<0.001 *$ & $7.800(3.099-19.632)$ & 0.982 & $1.039(0.038-28.339)$ \\
\hline HTN & $<0.001 *$ & $25.317(8.552-74.949)$ & 0.193 & $11.247(0.294-430.132)$ \\
\hline HF before (II + III + IV) & $<0.001 *$ & $143.182(17.553-1167.944)$ & 0.067 & $38.563(0.770-1930.690)$ \\
\hline CHADSVASC score & $<0.001 *$ & $8.364(3.693-18.944)$ & 0.289 & $2.741(0.426-17.651)$ \\
\hline Ischaemic time (M) & $0.026^{*}$ & $7.161(1.269-40.392)$ & 0.880 & $0.954(0.517-1.760)$ \\
\hline TIMI flow after (III) & $0.044 *$ & $0.370(0.141-0.974)$ & 0.381 & $4.235(0.168-106.996)$ \\
\hline
\end{tabular}

OR : Odd's ratio. $\quad$ \#: All variables with $p<0.05$ was included in the multivariate.

C.I : Confidence Interval. $\quad$ *: Statistically significant at $p \leq 0.05$.

Table (4): Agreement (sensitivity, specificity) for CHADSVASC score to predict CIN cases.

\begin{tabular}{lccccc}
\hline & $\begin{array}{l}\text { Cut } \\
\text { off }\end{array}$ & Sensitivity & Specificity & PPV & NPV \\
\hline $\begin{array}{l}\text { CHADSVASC } \\
\text { score }\end{array}$ & $>3$ & 55.56 & 98.44 & 95.2 & 79.7 \\
\hline
\end{tabular}

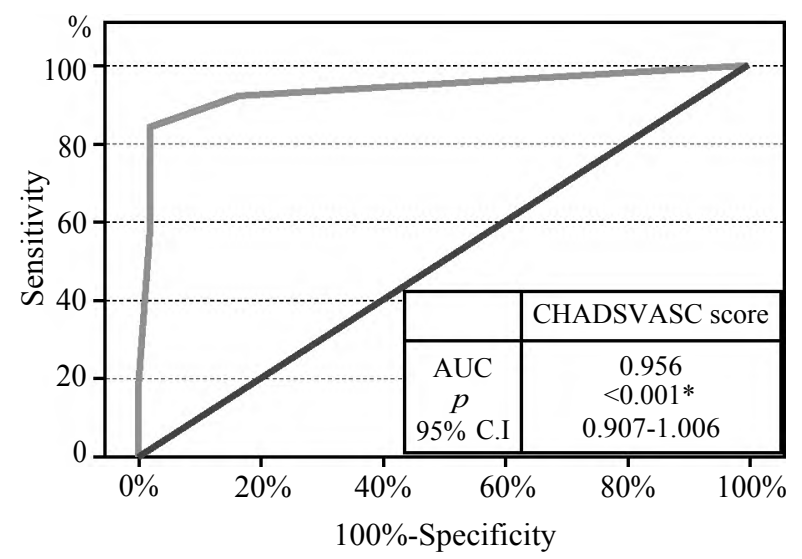

Fig. (1): ROC curve for CHADSVASC score to predict CIN cases.

\section{Discussion}

Acute ST-segment myocardial infarction is one of the most important cardiovascular diseases that increase risk of morbidity and mortality [1].

The primary goal in management of acute STEMI is reperfusion therapy with intravenous fibrinolysis or primary percutaneous intervention [2] .

Acute Kidney Injury (AKI) is a frequent complication among patients who undergo primary percutaneous intervention shown to be associated with adverse outcomes [3,4].

The reported incidence of CIN varies widely in different populations, ranging from $7 \%$ to $25 \%$, depending on the presence of risk factors. Hence, risk stratification is important, in order to apply the appropriate extent of prophylactic strategy in high-risk populations $[\mathbf{5 , 6 ]}$

In the aim of prevention of occurrence contrast induced nephropathy after primary PCI risk factors and predictors should be properly identified and well understood so that preventive measures and precautions could be applied.

The aim of this work is to evaluate CHA2DS2VASC score as a predictor for contrast-induced nephropathy in patient with acute myocardial infarction treated with primary percutaneous coronary intervention.

- As regarding age: In the present study, patients had been diagnosed with CIN post PCI were older than patients without CIN with mean (65.67 \pm 9.48$)$ ( $p$-value $<0.001)$.

In concordant to our study, Kurtul et al., [10] aimed for development and validation of a prePCI risk model for CIN prediction and included 159 patients who developed CIN showed that those patients tend to be older with mean age $(70.8 \pm 12.0)$ ( $p$-value $<0.001)$. Similarly, Inohara et al., [11] that aimed for development and validation of a prePCI risk model for CIN prediction and included 358 patients who developed CIN in a COHORT study showed that those patients tend to be older with mean age $72.1 \pm 12.1$. Similarly, Chou et al., study [12] reported that most of patients who had been diagnosed with CIN were more older in age compared with whom not diagnosed with CIN with mean (67.6 \pm 13.0 years), ( $p$-value $<0.001)$. Also Gurm et al., [13] reported that patients diagnosed with CIN post PPCI were more older than who not diagnosed with CIN with mean age $(70.3 \pm 12.3$ years) ( $p$-value $<0.001)$. In Andò et al., [14] reported that patients diagnosed with CIN post PPCI were more older than who not diagnosed with $\mathrm{CIN}$ with mean $(73 \pm 10)(p<0.001)$. 
- As regarding sex: The present study, there is significant correlation between sex with incidence of AKI as in Group I who developed CIN after primary PCI, 20 patients were female $(55.6 \%)$ while 16 patients were male $(44.4 \%)$. $(p=0.06)$. In concordant to our study, Kurtul et al., [10] showed that 72 from $159(45.3 \%)$ patients who developed CIN patients were female $(p<0.001)$. Similarly to our study, Inohara et al., study [11] also demonstrated CIN is commoner among female gender in their study. On the opposite side, Andò et al., [14] reported that (72\%) patients who were diagnosed with CIN post PCI were male and $73 \%$ of patient who were not diagnosed with CIN were male with no statistically significance between two groups according to sex $(p=0.63)$.

- As regarding diabetes mellitus: The present study, showed that there is statistically significant difference between the overall incidence of diabetes mellitus in the studied as in Group I, 25 patients $(72.2 \%)$ were found to be diabetics, ( $p$-value $<0.001)$. In concordant to our study, Kurtul et al., [14] demonstrated that diabetes mellitus as strong independent risk predictor for CIN. As 75 of 159 patients $(47.2 \%)$ who developed CIN after PCI were diabetic $(p<0.001)$. In concordant to our study, in a study carried on Italian patients by Evola et al., [15] to assess risk factors of contrast induced nephropathy $42 \%$ of 105 patients who developed CIN were found diabetics with ( $p$ 0.03) in comparison with those who did not develop AKI. Similarly, Merihan et al., [16] demonstrated that diabetes mellitus as strong independent risk predictor for CIN. As $19 \%$ of 729 patients who developed CIN after PCI were diabetic, in a multivariate logistic regression model (OR; 1.73-95\% Confidence Interval (CI) 1.48-2.02, ( $p<.0001)$. Also, Chou et al., [12], demonstrated that the DM is a strong independent risk predictor for CIN. In a logistic regression model (OR; 0.64-95\% Confidence Interval (CI) $3.06(1.72 \mathrm{e} 5.47)(p<0.001)$. Andò et al., [16], reported that $13(52 \%)$ patients diagnosed with CIN post PPCI were diabetic while 130 (29\%) patient who were not diagnosed with CIN post PCI were diabetic $(p=0.02)$.

-As regarding Hypertension: The present study, showed that there is statistically significant difference between the two groups as regard hypertension as in Group I, 29 patients (80.6\%) were hypertensive and 7 patients (19.4\%) were not hypertensive. $(p<0.001)$. In concordant to our study, Kurtul et al., [10], also demonstrated that hypertension as strong independent risk predictor for CIN. As 98 of 159 patients $(61.6 \%)$ who developed CIN after PCI were hypertensive $(p<0.001)$. In concordant to our study, Evola et al., [16] also demonstrated arterial hypertension was as strong independent risk predictor for CIN with $80 \%$ prevalence among their CIN group and $(p<0.05)$. Similarly, Merihan et al., [16] study also demonstrated hypertension as strong independent risk predictor for CIN. As $15.9 \%$ of 729 patients who developed CIN after PCI were hypertensive, in a multivariate logistic regression model (OR; 1.45-95\% Confidence Interval (CI) 1.24-1.71, $p<.0001)$. Also, in Andò et al., study [16] they reported that 21 (84\%) patients diagnosed with CIN post PCI were hypertensive while $264(58 \%)$ patient not diagnosed with CIN post PCI were hypertensive $(p=0.01)$.

- The present study showed that there was no statistically significant difference between the two groups as regard ischemic stroke, as in Group I, 2 patient $(5.6 \%)$ had ischemic stoke and 34 patients $(96.5 \%)$ didnt have $(p=0.294)$. In concordant to our study, Chou et al., [16] also demonstrated that the ischemic stroke was not a strong independent risk predictor for CIN, in a multivariate logistic regression model (OR; 0.64-95\% Confidence Interval (CI) 0.15-2.76, $p=0.548$ ). Disconcordant to our study, Kurtul et al., [10] also demonstrated that ischaemic stroke was a risk predictor for CIN was greater $(p=0.035)$. On the opposite side, Merihan et al., [16] also demonstrated ischemic stroke was an independent risk predictor for CIN, as $11 \%$ of patients had ischemic stroke and $18 \%$ of patient who developed CIN after primary PCI were having ischemic stroke. In a multivariate logistic regression model (OR; 1.37-95\% Confidence Interval (CI) $1.10-1.71, p=0007)$.

- As regarding peripheral artery disease: The present study showed that there was no correlation between peripheral vascular disease as a risk factor and AKI as no patients had peripheral vascular disease in this study. Disconcordant to our study, Merihan et al., [16] also demonstrated peripheral vascular diseases was an independent risk predictor for CIN, as $18 \%$ of patients had peripheral vascular diseases and $19.6 \%$ of patient who developed CIN after primary PCI were having peripheral vascular diseases, in a multivariate logistic regression model (OR; $1.61-95 \%$ Confidence Interval (CI) 1.35$1.93, p<0.0001)$.

- As regarding KILLIP class on admission: The present study showed that there is statistically significant correlation between clinical presentation of the patient on admission (KILLIP class) and AKI. $(p<0.001)$. In concordant to our study, Kurtul et al., [10] also demonstrated heart failure was a strong independent risk predictor for CIN, as 15 
of 159 patients $(15.7 \%)$ who developed CIN after PCI admitted with heart failure symptoms (KILLIP class $>2)(p<0.001)$ compared with who didnot developed CIN (3.5\%). Similarly, Chou et al., [12] also demonstrated that the congestive heart failure was a strong independent risk predictor for CIN. In a multivariate logistic regression model $(\mathrm{OR}$; $3.10-95 \%$ Confidence Interval (CI) 1.58-6.10, $p$ $=0.001$ ). Also, Merihan et al., [16] also demonstrated congestive $\mathrm{HF}$ was an independent risk predictor for CIN, as $38.5 \%$ of patient who developed CIN after primary PCI presented with heart failure symptoms on admission, in a multivariate logistic regression model (OR; 2.68-95\% Confidence Interval (CI) 2.09-3.44, $p<0.0001$ ). Gurm et al., [13] also demonstrated congestive HF was an independent risk predictor for CIN, as $40 \%$ of of patient who developed CIN after primary PCI presented with heart failure symptoms on admission ( $p=$ 0.001). Andò et al., [14] also demonstrated that congestive $\mathrm{HF}$ was an independent risk predictor for CIN as pre-procedural Killip class was found to be high in patient diagnosed with AKI post PCI compared to other group $(p=0.01)$.

- As regarding creatinin level: The present study showed, increasing creatinin level after primary PCI in Group I in which CHADS2-VASC score of the patient was higher compared to the other group in which CHADS2-VASC score was low $(p<0.001)$. In concordant to our study, Kurtul et al., study [10] showed increasing creatinin level in patients with high grade score with mean $1.34 \pm$ 0.45 compared to the other group in which patients have low grade score with mean $(1.04 \pm 0.24)(p$ $<0.001)$. Similarly, Merhan et al., study [16] showed increasing creatinin level after primary PCI, in a multivariate logistic regression model (OR; 2.053 95\% Confidence Interval (CI) $1.586-2.658, p$ $<0.0001)$.

- As regarding eGFR: The present study showed decreasing estimated GFR after primary PCI in Group I in which CHADS2-VASC score was higher $(>3)$ compared to the other group in which CHADS2-VASC score was low $(<3) .(p<0.001)$. In concordant to our study, Kurtul et al., [10] showed decreasing eGFR value in patients with high grade score with mean $52.4 \pm 19.5$ compared to the other group in which patients had lower grade score with mean $(75.5 \pm 18.6)(p<0.001)$. Similarly, Merhan et al., study [16] showed decreasing estimated GFR value after primary PCI, in a multivariate logistic regression model (OR; 1.194-95\% Confidence Interval (CI) $1.099-1.297, p<0.0001)$.

- As regarding contrast volume: In the present study, contrast volume was not found to have any statistically significance relation to the risk of developing AKI $(p=0.400)$. In concordant to our study, Kurtul et al., [10] also demonstrated total contrast volume used during PPCI was not a strong independent risk predictor for CIN, its amount during PCI did not differ between patients with or without AKI ( $179 \pm 71$ vs. $168 \pm 67$, respectively; $p$ $0.128)$. Similarly, data on contrast volume used were available in only 418 (38 had AKI) patients, however, its amount during PPCI did not differ between patients with or without AKI (134 \pm 49 vs. $147 \pm 47 \mathrm{~mL}$, respectively; $p 0.136$ ), or in multivariate models. Similarly, Andò et al., [14] , also demonstrated total contrast volume was not an independent risk predictor for CIN its amount during PCI did not differ between patients with or without AKI ( $165 \pm 79$ vs. $163 \pm 62 \mathrm{ml}$, respectively ( $p=0.88)$. Disconcordant to our study, Merhan et al., study [16] showed that there was correlation between contrast volume and developing CIN after primary PCI, in a multivariate logistic regression model (OR; 1.276-95\% Confidence Interval (CI) 1.197$1.360, p<0.0001)$.

- As regarding total ischemic time: In the present study, show that total ischaemic time of the patient was found to have statistical significant relation with the risk of developing AKI ( $p$-value $=0.004)$. In concordant to our study, Kurtul et al., study [10] also demonstrated that total iscaemic time and procedure time was not a strong independent risk predictor for CIN ( $p=0.034)$.

- As regarding TIMI flow: The present study, TIMI flow post procedure was found to have statistically significance relation with the risk of developing AKI $(p=0.04)$. In concordant to our study, Andò et al., study [14] also demonstrated that TIMI flow post procedure was a strong independent risk predictor for CIN as $19(76 \%)$ of patient who are diagnosed with AKI had TIMI III post procedure while $91.7 \%$ of patient who were not diagnosed with AKI had TIMI III post procedure $(p$-value $<0.001)$.

- As regarding hospital stay: In the present study, hospital stay for the patients who were diagnosed with CIN post PPCI was more prolonged than of the patients who were not diagnosed with CIN with statistical significance relation between two study groups regarding in-hospital stay ( $p$ $<0.001$ ). In concordant to our study, Andò et al., study [14] also demonstrated that in-hospital stay for patients who were diagnosed with AKI post PCI was ${ }^{9 \pm 5}$ days while patients who were not diagnosed with AKI post PPCI was ${ }^{7 \pm 3}$ days ( $p$ $<0.001$ ). 
- The present study show that CHADS2-VASC score was found to have have statistical significant correlation with the risk of developing AKI. ( $p$ value $<0.001$ ). In concordant to our study, Kurtul et al., study [10] show patients who developed AKI after PCI had high CHADS2-VASC score with mean $(4.25 \pm 1.48)$ while patients who didnot developed AKI after PCI had lower CHADS2-VASC score with mean $(2.68 \pm 1.49) .(p<0.001)$.

The present study demonstrated that the CHA2DS2-VASC score > 3 was independently associated with CIN development in patients with acute MI who were treated by PCI and the more CHADS2-VASC score, the more the incidence for developing CIN after PPCI.

\section{Limitations of the study:}

1- Small sample size.

2- The present study was single centre study.

3- Patients who presented with acute coronary syndrome (non-STEMI) were not included in this study.

4- Some confounders of CIN such as proteinurea could not be fully assessed.

\section{Conclusion:}

CHADS2-VASC score has been recently evaluated as a risk stratification tool for detection CIN after primary PCI. The present study demonstrated that the CHA2DS2-VASC score $>3$ was independently associated with CIN development in patients with acute STEMI who were treated by PCI. The more CHADS2-VASC score, the more risk for developing CIN after PCI.

\section{References}

1- STEG P.G., JAMES S.K. and ATAR D.: ESC Guidelines for the management of acute myocardial infarction in patients presenting with ST-segment elevation: The Task Force on the management of ST-segment elevation acute myocardial infarction of the European Society of Cardiology (ESC). Eur. Heart J., Oct., 33 (20): 2569-619, 2012.

2- O'GARA P.T., KUSHNER F.G. and ASCHEIM D.D.: ACCF/AHA Guideline for the Management of STElevation Myocardial Infarction: Executive Summary: A Report of the American College of Cardiology Foundation/ American Heart Association Task Force on Practice Guidelines. Circulation, Jan., 127 (4): 529-55, 2013.

3- SHACHAM Y., LESHEM-RUBINOW E. and STEINVIL A.: Renal impairment according to acute kidney injury network criteria among ST elevation myocardial infarction patients undergoing primary percutaneous intervention: A retrospective observational study. Clin. Res. Cardiol., Jul., 103 (7): 525-32, 2014.

4- AMIN A.P., SPERTUS J.A. and REID K.J.: The prognostic importance of worsening renal function during an acute myocardial infarction on long-term mortality. Am. Heart J., Dec., 160 (6): 1065-71, 2010.

5- RUDNICK M.R., GOLDFARB S. and WEXLER L.: Nephrotoxicity of ionic and nonionic contrast media in 1196 patients: A randomized trial. The Iohexol Cooperative Study. Kidney Int., Jan., 47 (1): 254-61, 1995.

6- BRAR S.S., SHEN A.Y.J. and JORGENSEN M.B.: Sodium Bicarbonate vs Sodium Chloride for the Prevention of Contrast Medium-Induced Nephropathy in Patients Undergoing Coronary Angiography. JAMA, Sep., 300 (9): $1038,2008$.

7- HUANG S.S., CHEN Y.H. and CHAN W.L.: Usefulness of the CHADS2 Score for Prognostic Stratification of Patients With Acute Myocardial Infarction. Am. J. Cardiol., Nov., 114 (9): 1309-14, 2014.

8- PICCINI J.P., STEVENS S.R., CHANG Y. and ROCKET A.F.: Steering Committee and Investigators. Renal Dysfunction as a Predictor of Stroke and Systemic Embolism in Patients With Nonvalvular Atrial Fibrillation Clinical Perspective. Circulation, Jan., 127 (2): 224-32, 2013.

9- CAPODANNO D., MINISTERI M. and DIPASQUA F.: Risk prediction of contrast-induced nephropathy by ACEF score in patients undergoing coronary catheterization. J. Cardiovasc. Med., Jul., 17 (7): 524-9, 2016.

10- KURTUL A., YARLIOGLUES M. and DURAN M.: Predictive Value of CHA2DS2-VASC Score for ContrastInduced Nephropathy After Percutaneous Coronary Intervention for Acute Coronary Syndrome. Am. J. Cardiol. [Internet]. Mar. 15, 119 (6): 819-25. Available from: http://www.ncbi.nlm.nih.gov/pubmed/28040187, 2017.

11- INOHARA T., KOHSAKA S. and ABE T.: Development and Validation of a Pre-Percutaneous Coronary Intervention Risk Model of Contrast-Induced Acute Kidney Injury With an Integer Scoring System. Am. J. Cardiol. [Internet]. Jun. 15, 115 (12): 1636-42. Available from: https://www. sciencedirect.com/science/article/pii/S0002914915009595. 2015.

12- CHOU R.H., HUANG P.H. and HSU C.Y.: CHADS2 score predicts risk of contrast-induced nephropathy in stable coronary artery disease patients undergoing percutaneous coronary interventions. J. Formos Med. Assoc., Jul., 115 (7): 501-9, 2016.

13- GURM H.S., SETH M., KOOIMAN J. and SHARE D.: A Novel Tool for Reliable and Accurate Prediction of Renal Complications in Patients Undergoing Percutaneous Coronary Intervention. J. Am. Coll Cardiol., Jun., 61 (22): 2242-8, 2013

14- ANDÒ G., TRIO O. and De GREGORIO C.: Risk Stratification of Contrast-Induced Acute Kidney Injury After Percutaneous Coronary Intervention: Should We Finally Get Rid of Procedural Variables? Am. J. Cardiol., Jul. 15, 116 (2): 337-8. Available from: https://www.sciencedirect. com/science/article/pii/S 0002914915011959, 2015.

15- EVOLA S., LUNETTA M. and MACAIONE F.: Risk factors for contrast induced nephropathy: A study among Italian patients. Indian Heart J., 64 (5): 484-91. Available from: http://www.ncbi.nlm.nih.gov/pubmed/23102387. 2012.

16- MEHRAN R., AYMONG E.D. and NIKOLSKY E.: A simple risk score for prediction of contrast-induced nephropathy after percutaneous coronary intervention. J. Am. Coll. Cardiol., Oct., 44 (7): 1393-9, 2004. 


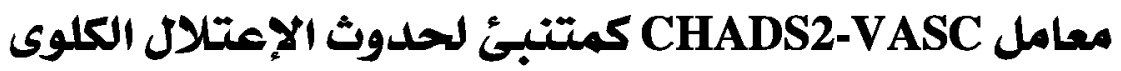

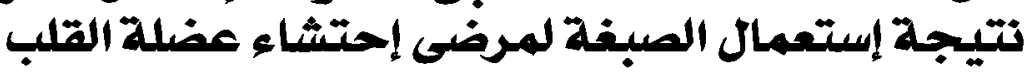

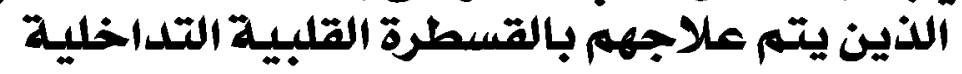

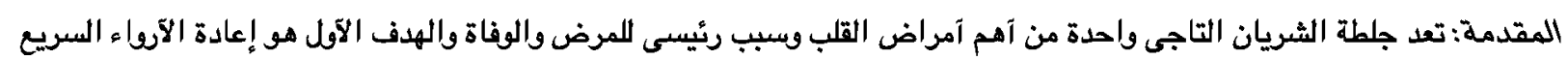

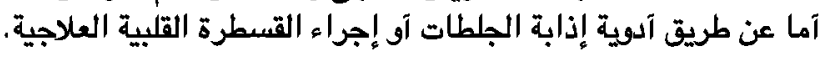

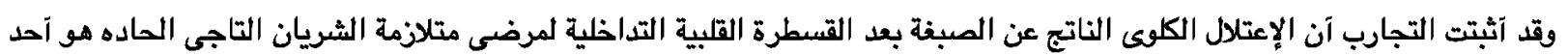

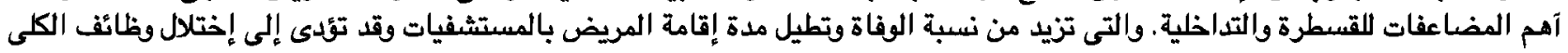
على المدى الطويل وإحتمال الغسيل الكلونى.

الإعتلال الكلى الناتج عن إستخدام الصبغة يعرف كزيادة نسبية آكثر من هب٪ من نسبة الكرياتنين الآولية آى زيادته ب ه ..مجم/لتر فى خلال ^^ع ساعة من إجراء القسطرة العناتع.

معدل حدوث الإعتلال الكلوى الناتج عن إستعمال الصبغة آثناء القسطرة يتراوح من بين V إلى ب ك فى الميه والتى يتوقف على مجموعة من العوامل المسبيه فى ذلك الكي.

ولقد آوضحت دراسات حديثة الإرتباط بين معامل الإتشاد فاسك وستو الحالة المرضية لمرضى إحتشاء عضلة القلب كما آوضحت قدرته

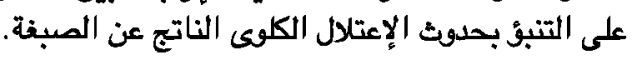

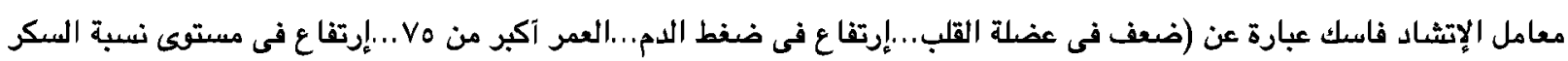

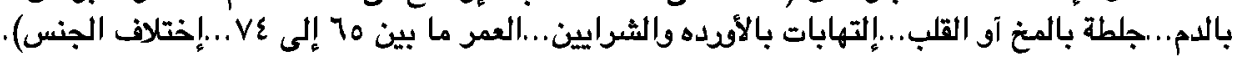

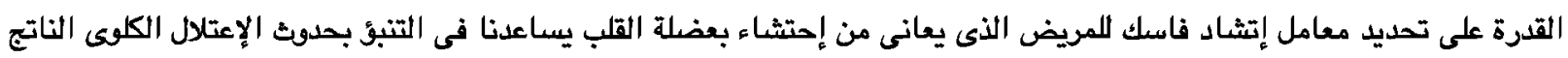

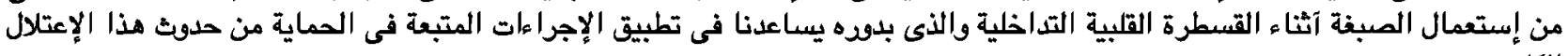
الكلوىن.

الهدف من البحث: دراسة المقدره التبوئية لمعامل CHADS2-VASC بحدوث الإعتلال الكلوى الناتج عن الصبغة بعد القسطرة القلبية التاخلية لمرضى متلازمة الشريان التاجى الحادها.

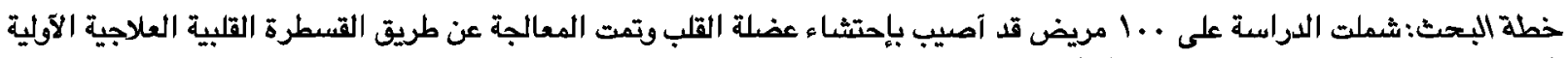

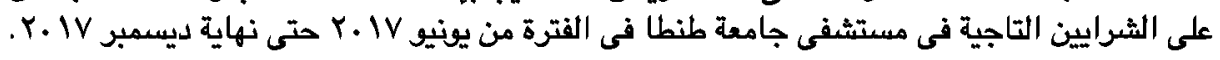

معايير الإستبعاد من البحث: البحن:

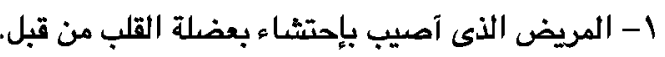

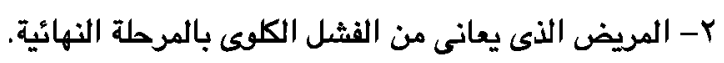

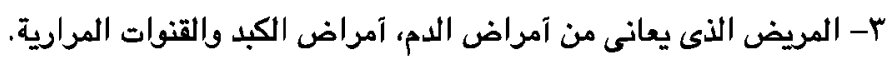

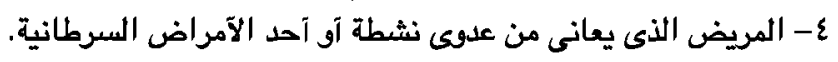

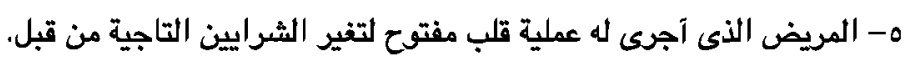

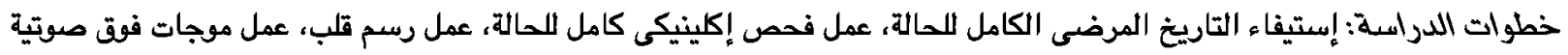

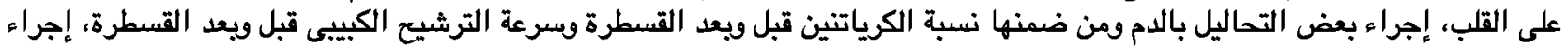

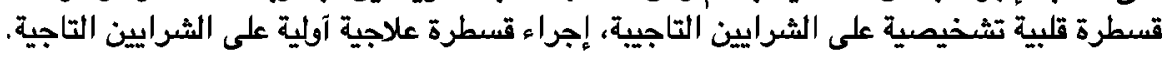

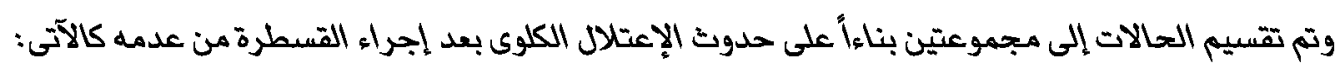

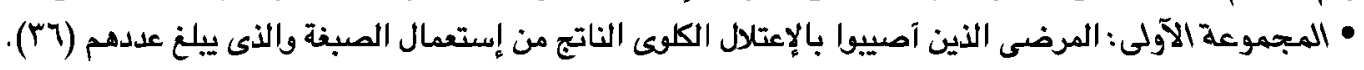

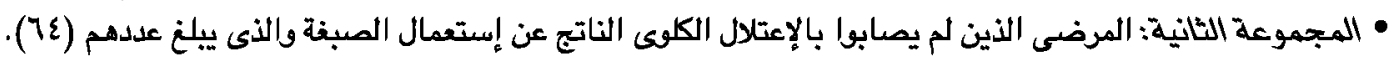

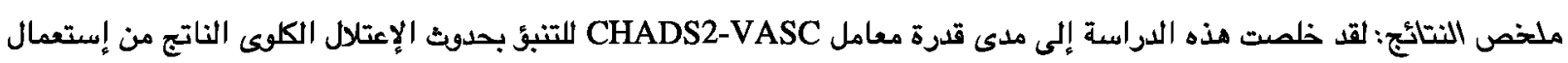

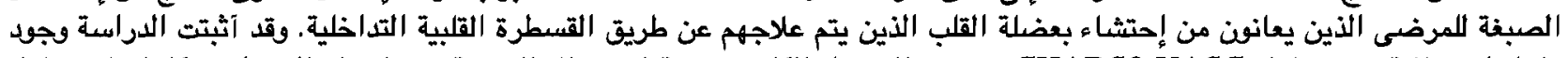

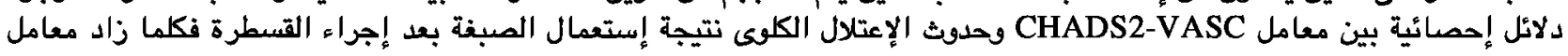

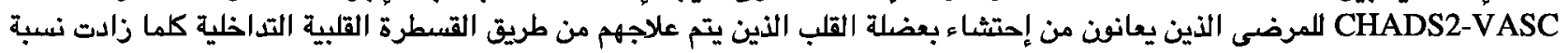

